\title{
EM DEFESA DO NASCITURO
}

\author{
Renato Luis Bueloni Ferreira \\ Aluno de Graduação da FDUSP
}

\begin{abstract}
Resumo: $O$ aborto é um dos temas mais polêmicos da atualidade e muitas vezes $\hat{e}$ analisado de forma superficial. Uma análise mais aprofundada, mostra que as razōes para que o aborto seja permitido são fragilmente fundamentadas e nāo vão de encontro aos avanços tecnológicos.

Abordamos no trabalho os aspectos médicos e ético-filosoficos para demonstrar que o aborto deve ser proibido. Em face destes estudos, torna-se hipócrita o artigo 128 do Código Penal, que permite o aborto.

Mostramos também que a personalidade jurídica do nascituro é a posição doutrinária mais fiel à tradição dos grandes civilistas brasileiros, devendo o feto ter proteção na ordem civil de seu direito à vida e ser reconhecido como sujeito de direitos.
\end{abstract}

Abstract: Abortion is one of most controversial subjects of our times and it is often analysed in a superficial way. A more profound analysis shows that the arguments for the permission of abortion are founded in weak evidende and do not accompany tecnological developments.

In this paper, we descussed the medical and the ethnical-philosophical aspects to demonstrate that abortion should be prohibeted. As the study shows, article 128 of the Penal Code, which permits abortions, becomes hypocritical.

Also, we demonstred that the juridical personality of the fetus is the doctrinary position which is more loyal to the tradition of the great Brazilian civil jurists; therefore, the fetus should have protection in the civil sphere of his/hers right to life and be recognized as a full person.

\section{Sumário}

I. Introdução.

II. Aspecto Etico-Moral.

III. Aspecto Médico.

IV. Aspecto Jurídico.

A) Do Âmbito Penal.

B) Do Âmbito Civil.

1. Pessoa e Personalidade.

2. O Artigo $4{ }^{\circ}$ do Código Civil.

V. Conclusão.

VI. Bibliografia 


\section{Introdução}

Com o decorrer dos anos, notamos uma tendência humana em reexaminar a história, redescobrir o passado e observar sociedades antigas para não cometermos os mesmos erros do passado no presente e no futuro. Pesquisamos o porquê da queda de grandes impérios ou a causa da desumanização de certas classes. Tomemos o escravo por exemplo. Hoje, percebe-se que o escravo $\ell$ um ser humano igual a todos os demais, independente de sua cor ou estado de nascença. Sentimos vergonha de falar deste período da história brasileira ou apontamos como uma das causas da queda do Império Romano.

A desumanização do ser humano. Como será que civilizações futuras nos verão? Indubitavelmente, acharam nobre a luta pelos direitos humanos e pela liberdade inerente ao ser humano. Porém, começarão a notar uma certa contrariedade, uma certa hipocrisia. Perceberão os imensos gastos para salvar baleias e o desprezo pelos famintos abandonados nas ruas das grandes cidades. Perceberão, também, que estes seres matavam seus próprios filhos antes de nascerem, por simples egoísmo ou comodismo.

O aborto é uma prova clara da desumanização do ser humano, do excesso de individualismo que assola a nossa sociedade. Referimo-nos ao aborto causado, que consiste na expulsão intencional do feto. do seio da mãe. Procuraremos demonstrar neste trabalho, que se trata de um homicídio doloso e enquadra-se tanto na ordem penal quanto na ordem civil, pois afeta o direito à vida do nascituro. Utilizaremos os vocábulos feto e nascituro como sinônimos.

\section{Aspecto Ético-Moral}

Partimos da posição de que o direito não se reduz à norma e portanto deve este defender na ordem jurídica a conduta moral do ser humano. Procuraremos nesta parte abordar o aspecto ético-moral e tentar chegar a uma conclusão do ponto de vista filosofico, se o feto já é ser humano.

Angel Rodriguez Luno afirma que "os governantes podem exigir que a conduta pública dos cidadãos respeite o conteúdo da lei moral natural". Portanto, se a lei moral natural garantir a proteção do nascituro, deve a ordem jurídica positivála.

Perguntar-nos-emos, primeiramente, o que é o homem? A resposta procede da Constituição Pastoral Gaudium et Spes de 7 de dezembtro de 1965, número 14, que declara: "O homem, ser uno, composto de corpo e alma, sintetiza em si mesmo, pela sua natureza corporal, os elementos do mundo material, os quais, por meio dele, atingem a sua máxima elevação e louvam livremente o Criador". Conclui-se que o homem tem uma parte espiritual e outra material. Parece-nos que hoje está havendo um inversão de valores, colocando como centro de todas as coisas o próprio homem, esquecendo-se da parte espiritual.

Mais adiante, a Gaudium et Spes ( $\left.n^{0} 26\right)$ afirma que "a consciência da eminente dignidade da pessoa humana, por ser superior a todas as coisas e os seus direitos e deveres serem universais e invioláveis", devendo estes serem protegidos pela ordem jurídica de cada país. Ademais, aponta a Constituição Pastoral ( $\mathbf{n}^{\mathrm{Q}} 27$ ) 
que "são infames as seguintes coisas: tudo quanto se opõe à vida, como seja toda espécie de homicídio, genocídio, aborto, eutanásia e suicídio voluntário". Nota-se, portanto, claramente, que o aborto não está de acordo com a natureza, pois priva o homem de um de seus mais preciosos dons, a vida. Na questão material, sabemos que o corpo é eterno; no âmbito espiritual, concordamos com a posição da imortalidade da alma, sendo esta defendida pelo magistério da Igreja e por São Tomás de Aquino, que fundamenta o porquê desta posição. Ademais, Platão e Aristóteles jă falavam na imortalidade da alma.

Rodriguez Luno concorda que "a vida é um dos maiores dons que o homem recebeu de Deus; é ilícito todo atentado direto contra o bem corporal de um inocente. Este dever impõe o respeito à vida e à integridade física alheia; dar e retirar a vida humana é um direito soberano de Deus". Portanto, só Deus pode criar e só Ele pode destruí-la. Deus porém, por ser infinitamente bom, não a destruirá e respeitará a sua liberdade. Deus une a alma ao corpo e estes separam-se apenas com a morte; morte esta que não pode ser causada por um ser humano, pois não é soberano sobre algo que não lhe pertença, no caso a vida alheia. A alma é infundida na carne no momento da concepção e passa-se a sujeitar apenas à consciência própria, respondendo o ser humano, somente a Deus pelos seus atos. Daí decorre a luta pelos direitos fundamentais, pois sem estes o ser humano não pode desenvolver a sua personalidade em plenitude.

Regis Jolivet, decano da Faculdade de Filosofia da Universidade Católica de Lyon, concorda que "o homem não $\epsilon$ autor nem, por conseguinte, o senhor absoluto de sua vida. Sobre esta tem ele só um domínio de uso, sujeito, aliás, por sua vez à lei moral. Não pode, pois, a seu talante renunciar à vida".

Eberhard Welty, professor da Universidade de Stuttgart, também afirma que "a vida humana existe onde houver uma alma imortal unida a um corpo mortal. Que este corpo esteja ou não plenamente formado, com todos os seus membros, não tem importância para o caso. Deus infunde a alma no próprio momento da concepção de uma nova vida no seio da mãe, e desde esse momento existe um homem. É certo que é uma vida que se deve desenvolver e crescer desde o germe até à sua plenitude, mas já é pessoa humana".

Conclui-se portanto que o nascituro já é ser humano desde a concepção e, portanto, deve ter a proteção da ordem jurídica. Percebe-se também que pelo fato de o homem não ser soberano sobre sua própria vida, nem sobre a vida de outrem, proíbe-se qualquer tipo de aborto voluntário e em qualquer circunstância.

\section{Aspecto Médico}

Com o aperfeiçoamento e desenvolvimento tecnológico da medicina, caminha-se a um consenso de que o feto é ser humano e que os meios modernos de salvação da mãe não justificam o aborto terapêutico.

Atualmente, a tecnologia consegue decodificar o código genético humano. Este código é um programa para o desenvolvimento do ser humano. Sabe-se também que o código genético de um indivíduo é diferente de todos os outros, não havendo dois iguais. $O$ espermatozóide, contendo parte do código genético do pai, e o óvulo, contendo parte do código genético da mãe, unem-se formando o zigoto e 
um novo indivíduo, pois surge um código genético individual, proprio e irrepettivel. Este código permanece inalterável da concepşão até 'a morte do indivíduo; Portanto, conclui-se que o feto não é parte do corpo da mãe e biologicamente já $́$ ser humano. A moderna biologia nada mais faz do que confirmar esta experiência elementar.

A outra questão muito discutida é a do aborto terapêutico. $O$ médico brasileiro João Evangelista dos Santos Alves, laureado em 1982 pela Academia Nacional de Medicina com o prêmio de Ética Médica, afirma que "o apelo ao chamado 'abortamento terapêutico' como meio de salvar a vida da gestante não constitui recurso cientifico, sobretudo nos dias atuais, em face das modernas conquistas da medicina". Andrew C. Varga em obra recente declara que "a medicina moderna tem meios de resolver a maioria dos problemas de saúde feminina relacionados com a gravidez, sem chegar ao aborto; a prática do aborto, em tais casos, se deve ou a imperícia do médico ou ao desejo de eliminar 'pela raiz'ou drasticamente o problema".

O testemunho é de peritos conceituados apesar de contradizer o texto do Código Penal. Cremos que cabe aos juristas dar atenção aos médicos, quando da decisão de normas que regulem matérias de caráter médico. $O$ professor francês, Jerôme Lejeune, finaliza, contradizendo os que afirmam ser o feto algo inerte: "Isso que tomais por uma mórula informe dir-vos-á um dia o que era, convertendo-se, como vós, mesmos, num homem".

\section{Aspecto Juridico}

\section{A) Do Âmbito Penal}

O nascituro, de modo geral, encontra proteção no Código Penal que proíbe o aborto. Os artigos 124, 125, 126 especificam e punem abortos cometidos pela gestante em si mesma, com ou sem o consentimento desta. Há apenas duas exceçōes à regra, que encontram-se no artigo 128. Este especifica:

"não se pune 0 aborto praticado por médico:

I - se não há outro meio de salvar a gestante;

II - se a gravidez resulta de estupro e o aborto $E$ precedido de consentimento da gestante, ou quando incapaz, de um representante legal".

Vimos e demonstramos na parte III, que o inciso I atualmente poderia ser derrogado pois os médicos já dispöem de meios suficientes para salvar a gestante. No caso do inciso II, o fim não justifica os meios. Andrew C. Varga, da Universidade de Fordham, clama que o "problema do início da vida humana é um problema cientifico, mas filosófico e ético". Portanto, o jurista deve fazer uma reflexão mais profunda e não apenas de acordo com o que é aceito pela sociedade, pois pode esta estar equivocada. Cremos e defendemos que a mãe não deve ter o direito de abortar, pois o feto é inocente e nada de culpa tem com a situação da mãe. Ora, a solução dada pelo Código Penal é de se resolver um ato mal com um muito pior, pois no segundo está em jogo a vida humana, que ao ser destruída implica homicídio. Logo, o inciso II, em caso de constatação de estupro, consente a pena de morte ao nascituro, que vai de choque frontal ao artigo $5^{\circ}$, inciso XIVII da Constituição Federal de 5 de outubro de 1988. Conclui-se que, também nestas 
exceções às regras, deve haver mudança para uma completa proibição do aborto em qualquer circunstância: Abordamos o âmbito penal, apenas para registro, pois nos propusemos a discutir o tema na ordem civil.

\section{B) Do Âmbito Civil}

1. Pessoa e Personalidade.

Os dois conceitos não devem ser confundidos. Orlando Gomes define pessoa da seguinte forma: "as pessoas naturais, ou físicas, são os seres humanos. Todo homem é pessoa". Clóvis Bevilaqua afirma que "pessoa é o ser a quem atribuem direitos e obrigações". Ora, o nascituro tem direitos e contrai obrigações, e portanto é pessoa.

O maior conflito está no conceito de personalidade. Adotaremos a definição dada pelo redator do Código Civil Brasileiro, Clóvis Bevilaqua, que declara ser personalidade "o conjunto dos direitos atuais ou meramente possíveis, e das faculdades jurídicas atribuídas a um ser".

Procuraremos na parte seguinte explorar estas definições.

\section{O artigo 40 do Código Civil.}

Quanto ao conceita de pessoa, não resta dúvida que o nascituro é pessoa, pois "É capaz de direito e obrigações na ordem civil". Porém, quanto à questão da personalidade a doutrina apresenta várias correntes.

O texto do artigo 42 e o seguinte: "A personalidade civil do homem começa do nascimento com a vida; mas a lei põe a salvo desde a concepção os direitos do nascituro". A questão é a seguinte: que direitos têm o nascituro? Indubitavelmente, o nascituro tem direitos pois o legislador não parou após "nascimento com vida", mas prosseguiu resguardando os direitos deste. O Código Civil especifica o direito de curatela (art. 462), doação (art. 1.169), direito a herança (art. 1.718) e reconhecimento de filho ilegítimo (art. 357). Nota-se que o nascituro é sujeito de direito. Surge uma contradição: como se pode ser sujeito de direitos e não ter personalidade jurídica?

Trataremos de duas correntes. A primeira que inclui os juristas Teixeira de Freitas, Clóvis Bevilaqua, Pontes de Miranda e José Tavares, é de que a personalidade começa com a concepção. O projeto do Código Civil Brasileiro de 1899 também assumiu a posição de que a personalidade civil do ser humano começa com a concepção. A Consolidação das Leis Civis de 1865 também concorda com tal posição. Percebe-se que a tradição civilista no Brasil $€$ a de que a personalidade civil se inicia com a concepção.

A outra corrente $\epsilon$ a da ficção, que inclui entre seus defensores Orlando Gomes. Para ele, apresenta-se um caso de personalidade fictícia pois a "a lei assegura direitos ao nascituro, se nascer com vida. Não tem personalidade, mas, desde a concepcão, é como se estivesse". Ora, mesmo sendo fictícia, o nascituro tem personalidade. "A questão da proteção dos interesses do nascituro tem sido focalizada por autores modernos, que não se mostram, entretanto, muito convencidos de que não haja reconhecimento de verdadeiros direitos, e, por conseguinte, admitem, de alguma sorte, a personalidade da criança, no tempo que vai da concepção ao nascimento". A posição de Eduardo Espínola demonstra uma 
certa fragilidade na teoria da personalidade fictícia, pois acaba-se por consentir que o nascituro tem personalidade. Defendemos esta posição e cremos que o nascituro é protegido pelo artigo $4^{2}$ do Código Civil.

\section{Conclusão}

Procuramos demonstrar que o feto $e$ um ser humano vivo e portanto suscetível de proteção jurídica. Parece-nos que uma interpretação extensiva do artigo $4^{2}$ do Código Civil garantiria a defesa do nascituro em plenitude na ordem civil. Propomos também, uma revisão do artigo 128 do Código Penal, para constatar se ainda é viável tal permissão. Cremos também que deve ser feita uma análise mais profunda do problema em todos os aspectos discutidos neste trabalho.

Finalizamos, comentando que nenhuma pessoa tem direito sobre outra pessoa e que o ser humano não é soberano sobre vida alheia. $O$ grande jurista português José Tavares concorda que "o direito sobre a própria pessoa é inadmissível mesmo quando referido ao seu elemento material ou corpóreo. Com efeito, tratando-se do corpo em vida, tal direito teria como necessária conseqüência o direito de suicídio, ... de provocar ou consentir o aborto..., e, em geral, de dispor por qualquer modo do próprio corpo ou da própria liberdade, como coisa que nos pertence. Ora, a verdade é que nenhuma legislação de povos cultos admite semelhantes direitos, que são incompatíveis com a própria dignidade humana e contrários à existência normal da sociedade".

\section{Bibliografia}

ALVES, João Evangelista dos Santos. Aborto Terapêutico e Ética Médica. Revista da Associação Médica Brasileira, v. 22, n.1, jan. 1976.

BEVILAQUA, Clóvis. Teoria Geral do Direito Civil. Rio de Janeiro : Liv. Francisco Alves, 1908.

CHAVES, Antonio. Estudos de Direito Civil. São Paulo : Ed. Revista dos Tribunais, 1979.

DE SANCTIS, Orlando, org. Encíclicas e Documentos Sociais. São Paulo : Ed. LTr, 1971.

ESPÍNOLA, Eduardo; ESPINOLA FILHO, Eduardo. Tratado de Direito Civil Brasileiro. Rio de Janeiro : Livr. Ed. Freitas Bastos, 1941. v.10.

ESTAL, Gabriel del. Derecho a la vida e Institución familiar. Madrid : EAPSA, 1979.

FREITAS, Augusto Teixeira de. Consolidação das Leis Civis. Rio de Janeiro : Tip. Universal de Laemmert, 1865. 
GOMES, Orlando. Introdução ao Direito Civil. 7.ed. Rio de Janeiro : Forense, 1983.

JOLIVET, Regis. Tratado de Filosofia Moral. Trad. de Geraldo Dantas Barreto. Rio de Janeiro : Agir, 1966. v.4.

LEJEUNE, Jerome. O princípio do ser humano. In. LAISSEZ les vivre. Paris : Ed. Pierre Lethielleux, 1975.

LUNO, Angel Rodriguez. Etica. Pamplona : EUNSA, 1982.

MESSNER, Johannes. Ética social. Trad. Alípio Maria de Castro. São Paulo : Quadrante, EDUSP, 1972.

NORONHA, Edgard Magalhães. Direito Penal. São Paulo : Saraiva, 1967. v.2.

ONDEI, Emilio. Le persone fisiche e $i$ diritti della personalita. Torino : Unione Tipogrtafico--Editrice Torinese, 1965.

PERLINGIERI, Pietro. La personalitá umana nell'ordinamiento giuridico. Camerino : Jovene Ed. 1972.

PONTES DE MIRANDA. Tratado de Direito Privado. Rio de Janeiro : Borsoi, 1955. v. 7 : Parte especial.

TAVARES, José. Os princípios fundamentais do Direito Civil. Coimbra : Coimbra Ed., 1922.

TOBENAS, José Castan. Los Derechos de La Personalidad. Madrid : Reus, 1952.

VARGA,.Andrew C. Problemas de Bioética. Trad. Pe. Guido Edgar Wenzel. São Leopoldo, RS : UNISINOS, 1982.

VILADRICH, Pedro-Juan. Aborto e a sociedade permissiva. Trad. José Gabriel P. Madureira. São Paulo : Quadrante, 1987.

WELTY, Eberhard. Catecismo social. Trad. Manuel da Costa Maia, Lisboa : Ed. Aster, 1960. v.2

São Paulo, setembro de 1989. 